\title{
Relevansi metode khalwat dalam proses pembelajaran pada masa pandemi COVID-19
}

\author{
Endin Mujahidin ${ }^{*}$ \& Zaenal Abidin Syamsuddin ${ }^{2}$ \\ ${ }^{1}$ Universitas Ibn Khaldun, Bogor, Indonesia \\ 2Ibnu Hajar Boarding School, Jakarta, Indonesia \\ *endin.mujahidin@uika_bogor.ac.id
}

\begin{abstract}
This study aims to examine the relevance of the seclusion (khalwat) method in the learning process during the COVID-19 pandemic. The method used is library research with an emphasis on analysis of classical references which are the source of the seclusion method. The results of the study indicate that the seclusion method is very relevant to be used in the learning process during the COVID-19 period with the following considerations: (1) The seclusion process takes place in three stages; separation, namely the process of separating oneself from the crowd; Initiation is the process of seclusion, concentration and dive deep within to find enlightenment; and return, namely returning to the social scene with a new vision. (2) The seclusion process is very in line with the psychological conditions of students where conditions require students to practice social distancing and stay away from crowds. (3) The seclusion method aims to foster calm within the perpetrator so that it can be used as an effort to overcome mental disorders of students caused by the COVID-19 pandemic.
\end{abstract}

Keywords: seclusion method, COVID-19 pandemic, online learning

\begin{abstract}
Abstrak
Penelitian ini bertujuan untuk mengkaji relevansi metode khalwat dalam proses pembelajaran pada masa pandemik COVID-19. Metode yang digunakan adalah library research dengan penekanan kepada analisis terhadap referensi klasik yang menjadi sumber dari metode khalwat. Hasil penelitian menunjukkan bahwa metode khalwat sangat relevan untuk digunakan dalam proses pembelajaran pada masa COVID-19 dengan pertimbangan, yaitu: (1) Proses khalwat berlangsung dalam tiga tahap; separation yaitu proses memisahkan diri dari keramaian; Initiation adalah proses mengasingkan diri, berkonsentrasi dan menukik jauh ke dalam diri untuk menemukan pencerahan; dan return yaitu kembali ke kancah pergaulan dengan visi baru. (2) Proses khalwat tersebut sangat inline dengan kondisi kejiwaan peserta didik di mana kondisi mengharuskan peserta didik untuk melakukan social distancing dan menjauhi keramaian. (3) Metode khalwat bertujuan untuk menumbuhkan ketenangan dalam diri pelakunya sehingga dapat dijadikan upaya untuk menanggulangi gangguan jiwa peserta didik yang diakibatkan oleh pandemik COVID-19.
\end{abstract}

Kata kunci: metode khalwat, pandemik COVID-19, pembelajaran daring

Diserahkan: 05-09-2021 Disetujui: 07-09-2021. Dipublikasikan: 08-09-2021

Kutipan: Mujahidin, E., \& Syamsuddin, Z. (2021). Relevansi metode khalwat dalam proses pembelajaran pada masa pandemi COVID-19. Ta'dibuna: Jurnal Pendidikan Islam, 10(3), 352-368.

doi:http://dx.doi.org/10.32832/tadibuna.v10i3.5358 


\section{Pendahuluan}

Pandemi COVID-19 banyak mengubah struktur kehidupan masyarakat, karena memunculkan kebiasaan baru berupa social distancing, menjaga jarak hingga kebijakan pembatasan sosial yang dilakukan secara masif. Hal itu membuat masyarakat harus mengurangi aktivitas bekerja, berbisnis dan belajar. Pandemi COVID-19 telah berdampak besar terhadap kondisi kesehatan baik fisik dan mental jutaan orang. Pada hari Kesehatan Mental Sedunia diperingati pada Sabtu, 10 Oktober 2020, Direktur Jenderal WHO, Tedros Adhanom Ghebreyesus menegaskan bahwa kesehatan mental menempati posisi strategis dalam kehidupan manusia di masa pandemi. Meskipun belum ada penelitian holistik yang mengukur dampak pandemi terhadap kesehatan baik fisik maupun mental, namun dampak pandemi dapat dibandingkan dengan temuan penelitian wabah MERS-COV pada tahun 2015 di Korea Selatan. Karantina saat wabah MERS di Korea Selatan dapat menyebabkan peningkatan level stres pada pasien hemodialisis (Ridlo, 2020). Kasus ini bisa memberi sinyal bahwa pandemi COVID-19 bisa menyulut gangguan jiwa dan kesehatan fisik seseorang hingga ke level yang amat memprihatinkan.

Dunia pendidikan adalah salah satu institusi yang paling terpuruk akibat pandemi COVID-19. Hal itu bisa dilihat dari hasil survei dengan metode self reporting questionnaire pada 44 remaja yang tergabung dalam Unit Kegiatan Mahasiswa (UKM), Universitas Negeri Semarang tahun periode 2019-2020 yang menyimpulkan bahwa sebanyak 63,6\% dari total responden terindikasi mengalami permasalahan kesehatan secara mental; (2) 26 dari total 44 responden atau 59\% merasa tegang, cemas atau khawatir selama 30 hari terakhir; (3) 22 orang dari total 44 responden atau 50\% merasa sulit untuk tidur selama 30 hari terakhir; (4) 22 orang dari total 44 responden atau 50\% merasa sulit untuk berpikir jernih selama 30 hari terakhir; (5) 22 orang dari total 44 responden atau 50\% merasa lelah sepanjang waktu selama 30 hari terakhir; (6) 9\% dari total responden memiliki pemikiran untuk mengakhiri hidupnya (Iqbal dan Rizqulloh, 2020).

Dengan demikian, di antara pihak yang rentan terkena stresor adalah remaja dan anak-anak, karena segala kegiatan yang biasa dilakukan di luar rumah berkurang drastis, dan bahkan seluruh masyarakat dihimbau untuk tetap berada di rumah. Akibatnya, pola hidup yang berubah ekstrem itu membuat semua kalangan terutama anak-anak dan remaja terpaksa harus bisa beradaptasi dengan kebiasaan baru tersebut. Apalagi mereka biasanya menghabiskan waktu aktivitasnya seperti bersekolah, bermain, dan lainnya di luar rumah (Ananda dan Aspari, 2020). Ketika berbagai gangguan jiwa tidak ditangani secara serius, maka dampak paling ringan adalah stres, sedangkan terburuknya adalah individu dapat melakukan bunuh diri. Di samping itu, stres juga dapat menyebabkan luka pada pencernaan, memicu gejala-gejala luka radang usus besar, dan penyakit radang usus. Otak juga rawan terhadap efek-efek stres jangka panjang yang berlangsung terusmenerus, termasuk kerusakan pada hipokampus, sehingga ingatan pun jadi rusak (Goleman, 2020) 
Semenjak munculnya kebijakan pemerintah dengan surat edaran no. 4 tahun 2020 dari Kemendikbud, yang menganjurkan seluruh kegiatan di institusi pendidikan harus melalui online dan seluruh penyampaian materi harus disampaikan di rumah melalui daring. Maka, setiap sekolah dituntut untuk membuat inovasi terbaru dalam proses pembelajaran yang sangat efektif dan efisien. Sudah banyak ditempuh oleh lembagalembaga pendidikan seluruh Indonesia, sebagian besar lembaga pendidikan sudah menemukan formulanya, meski belum ideal. Tetapi kebanyakan sekolah sudah bisa berakselerasi dan para orang tua peserta didik sudah beradaptasi. Apalagi pemerintah juga telah menggelontorkan dana cukup besar untuk mendukung sistem daring, dan bahkan Kemendikbud pun mengeluarkan regulasi seputar dana BOS yang cukup berpihak pada proses pembelajaran daring. Sayangnya, tidak serta merta semua institusi pendidikan rupanya paham betul mengenai inovasi terbaru yang harus dipakai untuk melakukan pembelajaran selama pandemi. Inovasi yang hendaknya digagas, terutama yang terkait dengan metodologi pembelajaran karena pengaruhnya yang sangat signifikan terhadap pencapaian tujuan pembelajaran (Ibrahim, 2014).

Putaran roda modernisasi telah menuntut manusia untuk meningkatkan kualitas hidup, karena modernisasi bergerak tidak membawa pesan moral dan nilai, sehingga cenderung akan sangat berdampak pada kehidupan manusia. Sedangkan pengaruhnya pada kesehatan mental dan kehidupan amat tergantung oleh kesiapan manusia menanggulanginya. Oleh karena itu, perlu bagi setiap manusia untuk menyiapkan diri, pikiran, dan hati dengan ilmu pengetahuan, memperbaiki hati, rohani dan pikiran yang rusak akibat modernisasi. Karena, manusia dituntut untuk beradaptasi dengan perubahan kehidupan yang memerlukan kebijaksanaan baru dan gagasan baru yang kreatif, karena tantangan hidup juga pasti baru dan lebih besar (Ikhsan, dkk., 2017).

Gangguan mental menjadi isu global dan krusial yang memerlukan penanganan terpadu, integral dan komprehensif, karena dampaknya signifikan, dan menimbulkan penderitaan berat secara kolektif serta dapat memperkeruh harmoni kehidupan. Faktor utama yang mempercepat tersebarnya gangguan jiwa adalah modernisasi (Fahmi, 1977). Dunia modern menampilkan dua peran antagonistis. Di satu sisi modernisme telah menghasilkan kemajuan di bidang sains dan teknologi. Tetapi sekaligus mencetak kemanusiaan modern penuh dengan kesengsaraan rohaniah (Suhaimi, 2015). Bahkan kehidupan semakin modern semakin terbebani dengan berbagai macam tuntutan yang harus dipenuhi. Bukan hanya bersifat primer atau penting melainkan hanya keinginan untuk diakui oleh masyarakat, maka menjadikan individu merasa harus mengikuti tren yang sedang berlangsung tanpa mengukur akan kemampuan dan kapasitasnya (Putri, dkk., 2015).

Nilai-nilai kepatutan dan kepatuhan memudar akibat pemujaan kepada materi. Bahkan tumbuhnya kekayaan material di Eropa berjalan seiring dengan meningkatnya 
angka bunuh diri (Promm, 1995). Di samping itu gangguan jiwa diperparah oleh pengaruh industrialisasi, yang menuntut berbagai macam perubahan yang ekstrem kemudian secara langsung dan tidak langsung akan memengaruhi kehidupan manusia (Notosoedirjo, 2014). Kebijakan kesehatan mental pada era modern dan industrial harus menjadi skala prioritas dan harus menjadi bagian kebijakan strategis dan integral dari kebijakan kesehatan mental global terutama akibat pandemi COVID-19. Karena semakin modern dan industrial suatu masyarakat semakin besar stresor psikososialnya, yang ditandai dengan ketidakpastian fundamental di bidang nilai, moral dan etika kehidupan, yang pada akhirnya bisa menimbulkan stres (Hawari, 1997).

Kesehatan mental masa pandemi COVID-19 makin terpuruk dan memaksa seseorang untuk menumbuhkan kesadaran tanggap darurat terhadap suatu persoalan, memiliki sikap penerimaan dan kemampuannya menyesuaikan diri. Kesehatan mental pula yang menentukan apakah orang akan mempunyai kegairahan untuk hidup atau akan pasif dan tidak bersemangat (Daradjat, 2016). Pandemi global menimbulkan perubahan besar pada struktur sosial dan ekonomi berupa pengangguran, perumahan karyawan, resesi ekonomi global, usaha stagnan, dan kriminal meningkat serta isolasi sosial. Ditambah lagi jumlah orang sakit dan orang mati meningkat tajam pasti berdampak besar pada kesehatan mental secara kolektif. Karena watak manusia sebagai makhluk bersosial (Ibnu Khaldun, 2004), sendirian dan terisolasi dapat menyebabkan situasi tidak aman. Adanya social distancing pasti akan menimbulkan jarak secara emosional antara keluarga, teman, dan sahabat. Begitu juga ketidakhadiran umat di tempat ibadah yang seharusnya bisa saling memberi kekuatan spiritual dan menimbulkan suasana kebersamaan (Lubis, 2016).

Sebuah survei yang diadakan oleh Kaiser Family Foundation di Amerika Serikat. Hasil survei tersebut menunjukkan bahwa hampir setengah dari orang-orang di AS merasakan krisis COVID-19 yang mana merusak kesehatan mental mereka. Survei yang dilakukan pada 25 hingga 30 Maret 2020 menemukan hasil bahwa 45\% orang dewasa mengatakan pandemi COVID-19 telah memengaruhi kesehatan mental mereka, dan 19\% mengatakan memiliki dampak besar terhadap kesehatan mentalnya (Iqbal dan Rizqulloh, 2020).

Secara umum terdapat enam langkah pokok untuk meningkatkan pelayanan kesehatan mental yang bisa dimasukkan sebagai program kesehatan mental pasca pandemi COVID-19, yang antara lain; 1) pelayanan yang menaruh perhatian pada diagnosis awal dan pengobatan yang secara tepat terhadap gangguan mental dan emosional; 2) usaha tindak lanjut dan rehabilitasi untuk seseorang yang tidak lagi menjadi pasien psikiatri rawat inap; 3) perlu konsultan untuk pelayanan kesehatan mental ke sekolah; 4) pendidikan publik terhadap pentingnya kesehatan mental; 5) diperlukan riset aksi sosial, untuk menemukan jawaban terhadap problem-problem yang mendasar berkaitan dengan gangguan-gangguan mental dan emosional, dan untuk 
mengevaluasi efektivitas program-program kesehatan mental yang baru atau unik; dan 6) berusaha untuk mencegah timbulnya gangguan mental (Notosoedirjo, 2014).

Adapun langkah strategis terkait dengan pembelajaran di masa pandemi COVID-19 agar keberhasilannya bisa terwujud dan berbagai masalah yang ditimbulkan bisa teratasi dengan baik, maka Raharjo (2020) mengusulkan lima langkah strategis, yang antara lain; 1) dilakukan peninjauan kembali terhadap target pembelajaran yang hendak dicapai, agar secara rasional selaras dengan situasi dan kondisi new normal; 2) mengidentifikasi sumber daya yang dibutuhkan agar tujuan baru yang telah ditetapkan dapat dicapai; 3) memetakan situasi dan kondisi masing-masing guru dan siswa yang harus bersiap-siap melakukan model pembelajaran baru berbasis blended learning; 4) menanggulangi kesenjangan antara kebutuhan dan ketersediaan sumber daya untuk menyusun langkahlangkah strategis dan operasional yang perlu segera dilakukan; 5) mengimplementasikan langkah-langkah yang telah dibuat secara kreatif dan inovatif dengan menjalin berbagai kemitraan dengan pihak-pihak eksternal.

Pakar pendidikan luar sekolah, Raharjo mengusulkan beberapa metode pembelajaran yang inovatif, sebagai solusi terhadap beberapa kendala proses pembelajaran yang antara lain; project based learning, daring method, luring method, home visit method, blended learning, dan memberi tugas dengan sistem steam. Metode pembelajaran STEAM (Science, Technology, Engineering, Arts, dan Mathematics) berfokus pada aspek kolaborasi, komunikasi, riset, mencari solusi, berpikir kritis, dan kreativitas. Sehingga, melalui metode STEAM, setiap murid dapat mengembangkan 5 C, yaitu Creativity, Collaboration, Communication, Critical Thinking, dan Character. Menurut Raharjo ada beberapa manfaat dari metode pembelajaran STEAM, antara lain; 1) peserta didik belajar berproses, melihat pola, mengasah keterampilan berpikir kreatif, kolaboratif, dan komunikatif; 2) peserta didik mengikuti pembelajaran yang menggunakan teknologi ilmiah dan kemampuan menyelesaikan masalah secara faktual; 3) peserta didik dilatih untuk berani menyampaikan ekspresi diri, baik kritik maupun pendapat. Hal ini meningkatkan kemampuan komunikasi verbal dan non verbal, sehingga anak akan bersikap terbuka kepada persepsi orang lain; 4) proses pembelajaran yang mengembangkan potensi peserta didik untuk membuat koneksi antara bahan pembelajaran, desain pembelajaran, serta alam sekitarnya; dan 5) peserta didik menemukan berbagai informasi yang dapat menuntutnya untuk berpikir kreatif dan kritis. Mereka didorong untuk memecahkan masalah baru bersama guru dan teman sebayanya (Rahardjo, 2020).

Selain metode tersebut di atas, salah satu metode yang dapat diusulkan adalah metode pembelajaran khalwat. Dalam khalwat berlangsung tiga tahap proses kejiwaan yang disebut separation, initiation dan return. Adapun separation adalah proses yang berlangsung dalam memisahkan diri dari keramaian, dan initiation adalah proses 
menciptakan kesendirian dan kesunyian, berkonsentrasi dan menukik jauh ke dalam diri, lalu menemukan pencerahan serta return adalah kembali ke kancah pergaulan masyarakat dengan visi baru. Setelah proses khalwat maka akan lahir pribadi-pribadi yang kuat (return), bukan pribadi yang asing terhadap lingkungannya.

Ada beberapa penelitian mengenai metode khalwat dalam konteks pendidikan tasawuf seperti yang dilakukan oleh Abdillah (2021), Mustofa (2018), dan Sismanto (2013). Namun penelitian-penelitian tersebut masih dalam konteks umum. Penelitian ini bertujuan lebih khusus untuk menguraikan metode khalwat dalam pendidikan Islam serta mengkaji relevansinya dalam proses pembelajaran pada masa pandemik COVID-19.

\section{Metode Penelitian}

Metode penelitian ini menggunakan metode literatur atau metode library research (penelitian kepustakaan) yang telah banyak dilakukan oleh para peneliti seperti Ardiansyah (2017), Al Hamat (2016) dan lain-lain. Berbeda dengan penelitian lapangan, maka lokasi pengumpulan data untuk penelitian kepustakaan jauh lebih luas, dan bahkan tidak mengenal batas ruang.

Teknik pengumpulan data melalui penggalian informasi dari referensi klasik untuk merumuskan metode khalwat dalam pendidikan Islam. Informasi yang sudah diperoleh sebagai data dan temuan dikumpulkan, diolah, dan dikelola kemudian ditinjau secara kritis dengan objek analisisnya adalah metode khalwat dalam pendidikan pada masa pandemik COVID-19. Analisis tersebut dilakukan untuk mengkaji situasi pembelajaran dengan sistem daring dan strategi penanggulangan dampak buruk dari daring dengan metode khalwat.

\section{Hasil dan Pembahasan}

\section{A. Metode Khalwat Sebuah Alternatif Pembelajaran}

Allah memerintahkan kepada setiap orang beriman agar memohon pertolongan dengan sabar dan salat sebagai bentuk ikhtiar bagi kesehatan jiwanya terutama pada masa pandemi (QS. Al-Baqarah: 45 dan 153). Orang yang terbiasa melakukan ibadahibadah yang disyariatkan akan terlatih untuk sabar menanggung beban, bertekad bulat untuk menciptakan rasa cinta dan berbuat baik kepada orang lain, serta memupuk spirit untuk melakukan interaksi sosial. Ketika orang yang tekun beribadah mengalami tekanan hidup, pengalaman emosi yang buruk, pertarungan batin yang menyebabkannya menderita penyakit jiwa, maka ibadah-ibadah tersebut dapat berfungsi sebagai media psikoterapi yang mujarab (Fuad, 2016). Bahkan berkaca pada hasil dari banyak penelitian klinis yang mencari hubungan antara komitmen agama dengan kesehatan fisik maupun kesehatan jiwa, ditemukan indikasi yang kuat bahwa komitmen agama bisa mencegah dan melindungi seseorang dari penyakit, atau mempertinggi kemampuan 
seseorang dalam mengatasi penderitaan dan mempercepat proses penyembuhan (Hawari, 1997.

Setidaknya terdapat empat faktor risiko utama depresi yang muncul akibat pandemi COVID-19, yaitu isolasi dan social distancing, tekanan ekonomi, stres dan depresi terutama pada pasien dan tenaga medis akibat stigma dan diskriminasi (Ridlo, 2020). Maka, dengan penguatan dimensi spiritual dengan penghayatan dan pengamalan agama yang sesuai dengan aturan syariat, dengan menjalankan perintah Allah dan menjauhi larangan-Nya, sebagai manifestasi keimanan dan ketakwaan (Imron, 2015), akan menjadi modal dasar untuk penanggulangan gangguan jiwa pasca pandemi. Oleh karena itu, metode khalwat bisa menjadi alternatif penanggulangan gangguan jiwa dari dimensi spiritual pada masa pandemi, menyeimbangkan stabilitas batin para peserta didik agar tetap prima dan tangguh dalam menghadapi proses pembelajaran dengan sistem daring. Melalui prosesi khalwat, peserta didik bisa mendapatkan kebeningan hati, ketajaman batin, kebersihan jiwa dan kesucian rohani. Bahkan, khalwat bisa menjadi stabilisator dan dinamisator kesehatan mental pada saat proses pembelajaran daring.

\section{Konsep khalwat}

Banyak pihak yang menisbahkan bahwa ibadah khalwat (retret) berasal dari tradisi kaum sufi dan dianggap sebagai ritual yang amat sakral untuk menaiki tangga tasawuf dan menapaki jalan zuhud di dunia. Oleh karena itu, Yahya bin Mu'adz menyatakan bahwa fondasi zuhud dibangun atas tiga asas; qillah (sedikit harta), khalwah (pengasingan) dan ju'u (lapar) (al-Qusyairy, 2008). Hakikat khalwat (retret) adalah pengasingan menuju pelarian kepada Allah sesuai dengan keterangan dalam Surat AlDhariyat ayat 50: "Segeralah kembali kepada Allah". Pelarian tersebut sebagai bentuk kembali kepada Allah, bertobat, meninggalkan sifat-sifat buruk, menjauhi maksiat lahir maupun batin, dan menuju totalitas perbaikan serta menghiasi diri dengan sifat-sifat terpuji. Pelarian Nabi Ibrahim kepada Allah dianggap oleh kaum sufi sebagai pijakan awal menuju prosesi khalwat seperti penjelasan dalam Surat As-Saffat ayat 99: "Sesungguhnya Aku pergi menghadap kepada Rabbku."

Khalwat sebagai bentuk mengasingkan diri, mengosongkan jasmani dan rohani dan menyibukkan pikiran dan perasaan untuk beribadah, bermunajat, dan berzikir kepada Allah dengan hati yang hadir dan khusyuk, serta tafakur tentang nikmat dan karunia-Nya di waktu siang dan malam hari. Oleh karena itu, khalwat pada hakikatnya ialah mengosongkan diri dari sifat-sifat buruk dan menggantinya dengan sifat-sifat yang terpuji, karena untuk sampai pada tangga kesalehan biasanya terhambat oleh awaaid (kebiasaan mendarah daging) berupa sikap suka santai dan bersenang-senang, dan awaaiq (hambatan) berupa syirik, bidah dan maksiat, serta alaaiq (ketergantungan) berupa kelezatan dan syahwat dunia, cinta ketenaran dan bergaul dengan manusia (Ibnul-Qayyim, 2001). Dalam rangka memangkas kebiasaan, hambatan dan 
ketergantungan tersebut, seorang hamba harus menempuh prosesi khalwat. Sehingga dengan khalwat, diharapkan akan memiliki hati yang bersih, mental yang sehat dan rohani yang bening dan menjadi insan kamil (manusia sempurna) yang berkepribadian utuh dan tidak asing dengan lingkungan sekitarnya. Bahkan bisa mengendalikan amarah, rendah hati, empati, menghargai orang lain, berpikir positif, pembawaan diri lebih tenang, berbicara seperlunya, makan dan tidur secukupnya, selalu muhasabah diri dan selalu mendapat ketenangan hati (Aini, 2019).

Khalwat juga bisa dijadikan sebagai wahana bertafakur untuk menyegarkan rohani dan menyehatkan mental, dan bahkan bisa menjadi sarana mujahadah untuk menemukan pengalaman batin dan spiritual yang intuitif, sehingga seseorang bisa menjadi hamba ar-Rahman yang paripurna (Ibnul-Jauzi, 2017). Oleh karena itu, Islam mendorong umatnya bertafakur untuk menemukan kebenaran (Hamka, 2015), yang melahirkan kebahagiaan abadi seperti penjelasan Surat Yunus ayat 101: Katakanlah: "Perhatikanlah apa yang ada di langit dan di bumi". (Yunus: 101).

Sesungguhnya aktivitas terbaik adalah bertafakur terutama bertafakur pada saat menjalani ritual khalwat, dalam rangka menemukan kebenaran dan pengalaman gaib melalui proses mujahadah. Ummu Darda' Radhiallahu Anha berkata, Bertafakur sejenak lebih baik daripada salat malam, maka ketika beliau ditanya, amalan apa yang paling utama bagimu? Beliau menjawab, bertafakur (Ibnul-Jauzi, 2004). Sedangkan kebenaran yang diperoleh melalui tafakur dapat dibedakan menjadi dua jenis; (1) pengetahuan yang didapatkan sebagai hasil usaha aktif manusia untuk menemukan kebenaran, baik melalui penalaran maupun lewat kegiatan lain seperti perasaan dan intuisi (ilmu hushuli); (2) pengetahuan yang bukan merupakan kebenaran yang didapat sebagai hasil usaha aktif manusia, tapi kebenaran yang ditawarkan dan diberikan oleh wahyu (ilmu hudzuri) (Sumantri, 2010).

Ketika berkhalwat, seseorang bisa melakukan mujahadah untuk mendapatkan kebenaran dan pengalaman gaib, tetapi terkadang pengalaman gaib yang diperoleh melalui mujahadah untuk memuliakan orang yang beriman tidak bersifat tetap. Seseorang yang jiwanya bersih, iman dan takwanya tinggi, dan kebeningan jiwanya bisa menyentuh hatinya. Allah akan berikan sesuatu yang bersifat gaib ke dalam hatinya. Hal itu pernah disinggung al-Ghazali dengan sebutan ilham (kasyaf). Akan tetapi proses mujahadah, kadang membawa dampak buruk, dan jiwanya bisa diperdaya berbagai imajinasi yang disangka sebagai "esensi" yang turun, kecuali mereka yang mampu memenuhi persyaratan sebagai berikut: (1) mempunyai bakat genius, yang sejak kecil tertarik dengan problem-problem keilmuan yang fundamental dan siap untuk memahami ilmu-ilmu; (2) tumbuh dan dibesarkan dalam mencari ilmu, serta terlatih dan menguasai betul aneka disiplin ilmu; dan (3) memiliki ilmuwan pembimbing yang 
mandiri dalam penemuan dan penguasaan ilmu-ilmu dalam arti yang sebenarnya (Anwar, 2007).

\section{a. Anjuran Khalwat}

Khalwat secara bahasa menyepi (Ibrahim, dkk., tt.), sedangkan menurut istilah, khalwat adalah ritual ibadah menyepi dan mengasingkan diri dalam rangka mendekatkan kepada Allah, yang berasal dari tradisi kaum sufi, yang hampir mirip dengan itikaf (Ibrahim, 1995). Bahkan, dalam pandangan Walisongo bertapanya (meditasi) seorang muslim adalah dengan salat berjamaah dan itikaf (Drewes, 2002). Sehingga khalwat merupakan prosesi ibadah yang ditekuni oleh orang-orang suci (Qusyairy, 2008) sebagai langkah takhliah yaitu pembersihan diri dari sifat-sifat tercela menuju kepada tahliah yaitu penghiasan diri dengan sifat-sifat yang terpuji. Sehingga khalwat merupakan prosesi untuk mengosongkan diri dari sifat-sifat buruk dan mengisinya dengan sifat-sifat yang terpuji (Aini, 2019). Demikian itu sebagai bentuk inabah (kembali) kepada Allah secara totalitas seperti penjelasan Surat az-Zumar ayat 54: Dan kembalilah kalian kepada Rabb kalian. Sedangkan inabah bisa diterima oleh Allah setelah memenuhi empat unsur, yaitu; mencintai Allah, tunduk kepada-Nya, menghadap kepada-Nya dan berpaling dari selain-Nya (Ibnul-Qayyim, 2005).

Dan khalwat juga sebagai bentuk firaar (pelarian) kepada Allah seirama dengan anjuran Surat Al-Dhariatiyat ayat 50: Segeralah kembali kepada Allah. Hakikat firar (pelarian) adalah bersegera kepada ketaatan dan pahala Allah, serta menjauhi maksiat dan siksaan-Nya (az-Zamakhsyary, 2008). Oleh karena itu, hakikat khalwat adalah keinginan menyepi untuk menghadap Allah, melakukan Itikaf dan mengasingkan diri sebagaimana yang dilakukan oleh Nabi Musa selama 40 hari di Thur Sina', Maryam putri Imran di mihrab selama 3 hari, dan Nabi Muhammad selama bulan Ramadhan di Gua Hira. Demikian itu mereka lakukan dalam rangka nyepi, pengasingan, pelarian dan kembali kepada Allah. Dan khalwat merupakan ibadah yang lebih dekat dengan ritual itikaf, sehingga hukum, hikmah, adab, syarat serta keutamaannya lebih mungkin dikiaskan dengan ibadah Itikaf (Ibrahim, 1995).

\section{b. Hikmah Khalwat}

Kelurusan hati menuju Allah sangat bergantung kepada kuat dan tidaknya hati berkonsentrasi mengingat Allah dan kekuatannya dalam mengurai kusutnya hati dengan menyerahkan diri secara totalitas kepada Allah. Ada beberapa hal yang bisa menjadikan hati berkonsentrasi yang akhirnya kusutnya hati pun terurai yaitu dengan tidak makan dan minum secara berlebihan, mengurangi banyak tidur dan tidak banyak berbicara melalui ibadah Itikaf sebagai manifestasi dari khalwat. Karena berlebihan makan, minum, tidur dan berbicara akan membutakan hati dan menghambat perjalanannya menuju Allah (Syamsuddin, 2017). 
Oleh karena itu, khalwat bisa memulihkan rohani yang kusut, hati yang keras, batin yang kotor, pikiran yang penat dan stres akibat tekanan hidup yang ekstrem selama pandemi. Sementara bila dibiarkan, akan mengakibatkan berbagai penyakit rohani dan gangguan jiwa serta berdampak pada iman melemah, malas beribadah dan kendur dalam beramal saleh. Maka, khalwat merupakan seremonial untuk menyegarkan kondisi batin yang kusut, menyirami jiwa yang gersang dan menyeimbangkan pikiran yang guncang. Saat khalwat, seorang hamba bisa melakukan muhasabah dan mengingat kematian serta persiapan menuju akhirat. Akhirnya pasca menjalani khalwat, seseorang akan memiliki rohani yang bugar, batin yang segar dan pikiran rileks. Bahkan pasca khalwat ia akan menjadi insan yang sehat baik secara fisik dan psikis.

\section{c. Tujuan Khalwat}

Seorang hamba harus bisa menyisihkan waktu untuk berkhalwat dengan Rabbnya dalam rangka menyingkirkan kerumitan, krisis dan residu psikologinya, membersihkan dosa-dosanya dan meluruskan tingkah lakunya dan menyegarkan kualitas keimanan dan kedekatan dengan Rabbnya. Sehingga hatinya bening, batinnya cerah, penyakit hati hilang, psikologis dan moralnya sembuh, makin dekat dengan Rabbnya dan terlahir kembali dalam kondisi sehat jasmani dan rohani. Oleh karena itu, tujuan utama khalwat adalah menjadi ajang penyembuhan penyakit jiwa (Ibrahim, 1995). Di samping itu, ibadah khalwat bisa menciptakan emosi stabil, sabar menerima cobaan dan tahan banting dalam menghadapi musibah (Aini, 2019). Khalwat juga sebagai bentuk isolasi mandiri dalam rangka menjalani proses penyembuhan penyakit rohani dan mencegah agar virus-virusnya tidak menular kepada orang lain sebagaimana penanganan penyakit jasmani yang menular, Bahkan penyakit rohani lebih bahaya penularannya, lebih besar malapetakanya dan kematian rohani lebih buruk dampaknya (Farid, 2018).

\section{Teknis metode khalwat}

a. Syarat-syarat Khalwat

Apabila ritual khalwat dianggap sebagai manifestasi ibadah itikaf, maka khalwat tidak sah kecuali setelah memenuhi beberapa syarat antara lain, Islam, berakal, balig, niat dan dilakukan di dalam masjid. Para ulama berbeda pendapat apakah seorang yang beritikaf harus dalam keadaan berpuasa? Demikian pula mengenai jangka waktu beritikaf. Namun pendapat paling kuat adalah tidak disyaratkan harus berpuasa dan tidak ada pembatasan waktu secara khusus. Dan inilah pendapat yang dipilih (Bin Baz, 1423 H). Akan tetapi mengenai tempat terdapat perbedaan antara khalwat dengan Itikaf, di mana Itikaf harus di masjid, sementara khalwat bisa di tempat selain masjid, namun masjid lebih diutamakan untuk pelaksaan khalwat.

b. Macam-macam Khalwat

Tata cara dan pelaksaan ritual khalwat berbeda-beda tergantung kondisi masyarakat dan bimbingan penasihat spiritual kepada muridnya. Demikian itu sangat bergantung 
pada kesiapan, kesempatan, kemampuan, dan kebutuhan yang bersangkutan. Namun secara umum khalwat terbagi menjadi tiga macam; 1) khalwat kamilah (total); 2) khalwat juz'iyah (parsial); dan 3) khalwat jalwah (pararel) (Ibrahim, 1995).

\section{Khalwat Kamilah (Total)}

Khalwat Kamilah (Total) merupakan bentuk isolasi total dalam jangka waktu tertentu, meskipun sekali seumur hidup dan tidak berulang lagi, dalam rangka mencari keutamaan. Bisa dilakukan di mana saja, tetapi dilakukan di masjid lebih utama sebagaimana Nabi Muhammad berkhalwat di Gua Hira' dan Nabi Musa di Thur Sina' serta Maryam di Mihrab.

\section{Khalwat Juz'iyah (Parsial)}

Khalwat Juz'iyah (Parsial) mengisolasi diri untuk beribadah setiap hari di tempat tertentu dan waktu tertentu meskipun sesaat, setelah menyelesaikan tugas-tugas hariannya. Adapun tata caranya; menjaga anggota tubuh dan hati sepenuhnya dari halhal yang dilarang oleh Allah saat bersama manusia. Segera bertobat dari berbagai macam kesalahan baik besar maupun kecil, sambil terus-menerus menyibukkan diri dengan zikir-zikir pilihannya. Meskipun lisan terdiam, hati tetap terus menerus mengingat Allah.

\section{3. khalwat jalwah (pararel)}

khalwat jalwah (pararel) adalah menyibukkan hati untuk mengingat Allah, meskipun anggota tubuhnya sedang beraktivitas untuk bekerja dan memenuhi kebutuhan hidupnya, dan bahkan aktivitas hariannya tidak mengganggu hubungannya dengan Rabbnya. Sehingga moto hidupnya "hati bersama sang khalik, sedangkan tubuh bersama makhluk" dalam arti, ia bersama Allah dengan rohaninya dan bersama makhluk dengan jasmaninya. Dengan demikian, dia terus menerus menjaga anggota tubuh dan gerak geriknya ketika beraktivitas dan menekuni tugas-tugas harian untuk tidak melakukan hal-hal yang dilarang. Dia tidak menyepi secara total maupun parsial, namun ia menyepi secara pararel. Artinya dia berada di tengah keramaian dan kesibukan duniawinya, tetapi secara pararel hatinya tetap tersambung dengan Rabbnya. Sehingga dia senantiasa meluruskan niatnya dalam setiap ucapan, perbuatan dan gerak-geriknya.

c. Jumlah zikir

Hendaknya seorang yang menjalani khalwat juz'iyah (parsial) dan khalwat jalwah (pararel), menyesuaikan jumlah zikirnya dengan kondisi dan tuntutan hidupnya, agar tidak tersibukkan dengan menghitung jumlah zikir dengan alat tertentu seperti tasbih atau lainnya. Sehingga tidak mengganggu kesibukannya dan tidak memancing perhatian orang-orang sekitarnya, sehingga rusak amalnya dengan riya' dan sum'ah. Meskipun jumlah zikir penting, tapi ia harus memperhatikan kesiapan, keadaan, tempat, aktivitas dan kesiapannya, sehingga tetap dapat menunaikan khalwatnya secara baik di sela-sela kesibukannya.

d. Tata Cara dan Adab Khalwat 
Seorang yang hendak menjalani ritual khalwat harus menyempurnakan keikhlasannya, menghadirkan seluruh keperluan selama khalwat baik berupa makanan, minuman, dan seluruh keperluannya. Selama berkhalwat sebaiknya berpuasa, atau setidaknya mengurangi makan dan minum. Pada saat khalwat hendaknya mengurangi tidur, tidak berlebihan dalam berbicara dan menghindari hal-hal yang sia-sia. Bahkan ia harus berkonsentrasi, menghadap Allah, bertawakal kepada-Nya dan fokus beribadah. Bila ingin memulai khalwat, hendaknya melakukan hal-hal berikut ini; 1) membebaskan diri dari sangkutan dan tanggungan orang lain; 2) memenuhi kebutuhan keluarganya selama berkhalwat; 3) mengatur pekerjaan, usaha dan perniagaannya agar tidak terhenti dan mandek. Kemudian mandi dengan niat Itikaf dan khalwat lalu mengenakan minyak wangi kemudian salat tobat, dan memenuhi syarat-syarat bertobat (Ibrahim, 1995). Diutamakan berkhalwat pada hari Jumat, menyibukkan diri dengan membaca al-Qur'an, membaca shalawat, membaca surat al-Kahfi, memperbanyak zikir dan bersungguhsungguh dalam berdoa setelah salat Ashar, serta menjaga agar dia tidak terjatuh ke dalam pelanggaran syariat selama berkhalwat.

\section{e. Tempat Khalwat}

Di muka telah disinggung bahwa ada perbedaan mengenai tempat antara khalwat dan Itikaf. Ritual khalwat bisa dilakukan di mana saja meskipun diutamakan di masjid. Adapun Itikaf tidak sah kecuali di masjid, dan bahkan sangat dianjurkan di masjid jami yaitu masjid yang mengadakan salat Jumat agar tidak perlu keluar ke masjid lain untuk salat Jumat berdasarkan firman Allah Surat al-Baqarah ayat 187: "(Tetapi) janganlah kamu campuri mereka itu, sedang kamu beritikaf dalam mesjid." (Al-Baqarah: 187)

Adapun maksud perkataan Hudzaifah, Ibnu Abbas dan Hasan bahwa tidak ada itikaf kecuali di tiga masjid, Masjidil Haram, Masjid Nabawi, Masjidil Aqsha (HR al-Baihaqi). Maksudnya tidak ada itikaf karena nazar untuk safar kepadanya kecuali ke tiga masjid tersebut atau tidak ada itikaf paling sempurna kecuali di tiga masjid tersebut. Karena para ulama terutama para imam mazhab sepakat sahnya itikaf di setiap masjid bukan hanya di tiga masjid di atas saja.

\section{f. Waktu Khalwat}

Jika seseorang berniat ingin berkhalwat dalam bentuk ibadah itikaf untuk mendekatkan diri kepada Allah, maka paling utama dilakukan pada bulan Ramadhan. Waktunya terhitung sejak berniat beritikaf hingga ia keluar dari masjid. Jika niat itikaf semalam, maka ia harus masuk masjid sebelum matahari terbenam dan keluar setelah fajar terbit. Dan jika berniat di siang hari, maka ia harus masuk masjid sebelum fajar terbit dan tidak keluar dari masjid hingga matahari terbenam. Bila seseorang berniat itikaf pada sepuluh terakhir bulan Ramadhan, hendaklah ia memasuki tempat itikaf sebelum matahari terbenam menjelang malam kedua puluh satu. Dan dianjurkan 
meninggalkan tempat itikaf pada hari terakhir bulan Ramadhan setelah matahari terbenam pada malam Idul fitri.

g. Amalan-amalan Ketika Khalwat

1. Amalan-amalan yang Dianjurkan

- Memperbanyak ibadah, seperti salat, tilawah al-Qur`an, membaca buku-buku Islam dan lain-lain.

- Menjauhkan diri dari ucapan kotor seperti berdebat, mencela, memaki dan lain-lain.

- Berdiam di dalam masjid untuk beribadah, bermunajat, bertafakur dan muhasabah.

2. Amalan Yang Dibolehkan

Keluar dari masjid untuk suatu keperluan yang mendesak. Berdasarkan hadis sahih dari Aisyah bahwa ia berkata, "Tuntunan bagi orang yang sedang beritikaf adalah tidak boleh menjenguk orang sakit, tidak boleh penyelenggaraan jenazah, tidak boleh bercumbu dan menggauli istri dan tidak keluar dari tempat itikaf kecuali untuk suatu keperluan yang mendesak, tidak boleh itikaf kecuali dengan puasa serta tidak boleh itikaf kecuali di masjid Jami'." (HR. Abu Daud).

- Boleh makan, minum dan tidur di dalam masjid dengan tetap menjaga kebersihan.

- Boleh berbicara dengan orang lain untuk suatu keperluan.

- Merapikan rambut, memotong kuku, memakai pakaian bagus, mandi dan memakai minyak wangi berdasar hadits Aisyah berkata, "Ketika Rasulullah sedang beritikaf di dalam masjid, beliau mengeluarkan kepalanya dari sela-sela kamar, kemudian aku mencuci dan menyisir rambut kepalanya." Dalam riwayat lain, "Kemudian aku merapikan rambutnya (Bukhari No. 301 dan Muslim No. 297).

- Melepaskan kepulangan keluarga yang menjenguknya, berdasarkan hadits Shafiyah yang mengabarkan bahwa Rasulullah melakukannya.

3. Amalan yang Dimakruhkan

Dimakruhkan ketika berkhalwat dalam bentuk ibadah itikaf bertransaksi jual beli, berbicara yang mendatangkan dosa seperti gibah dan namimah atau tidak berbicara sama sekali dengan keyakinan bahwa demikian itu adalah ibadah.

\section{B. Implementasi Metode Khalwat Dalam Pembelajaran Daring}

Pada masa pandemi telah ditemukan terobosan model pembelajaran dengan metode daring, yang menuntut setiap peserta didik anak secara aktif mampu menggunakan perangkat teknologi gadget atau komputer. Dengan kemudahan yang ditawarkan oleh teknologi, para peserta didik mampu mengikuti proses pembelajaran dari rumah-rumah masing-masing secara efektif dan efisien.

Ternyata kemudahan tersebut memberikan perspektif yang berbeda bagi para peserta didik yang berusia remaja. Justru pada saat proses KBM sedang berjalan, 
sebagian mereka tersibukkan dengan membuka Facebook, Instagram, Youtube dan lainnya. dalam usia pubertas, masa terlihat cantik ataupun ganteng, ingin diperhatikan, ingin melihatkan eksistensinya, ingin mencari kenyamanan dan lain sebagainya. Pada saat proses KBM kadang ada yang menjadikan sebagai ajang perlombaan mengekspos foto, dengan gaya yang indah namun memancing masalah. Namun keindahan itu dimanfaatkan oknum yang tidak bertanggung jawab, yang akhirnya terjadi kriminalitas, penculikan, kejahatan seksual, pembunuhan dan lain sebagainya (Gani, 2019).

Dari perspektif psikologi transpersonal, khalwat bisa dimaknai sebagai teknik untuk mengubah, memfokuskan, memecahkan, atau memperluas kesadaran normal. Sehingga metode khalwat bisa digunakan untuk mengembalikan para peserta didik yang tersibukkan dengan hal-hal yang negatif pada saat KBM berlangsung dan terjebak dengan hingar bingar dunia maya dengan mengunggah berbagai macam foto atau tulisan yang tidak bermanfaat. Melalui ritual khalwat baik parsial maupun pararel akan mampu mengembalikan kesadaran mereka yang hilang akibat sabotase sosial media, sehingga mereka bisa kembali fokus lagi kepada kegiatan KBM. Karena hakikat khalwat adalah pengosongan jasmani dan rohani dari sifat buruk dan mengisinya dengan sifat terpuji dengan mengasingkan diri di suatu tempat, memutuskan hubungan dengan manusia dan meninggalkan segala aktivitas duniawi dalam waktu tertentu, serta mengisinya dengan zikir dan ibadah kepada Allah (Aini, 2019).

Oleh karena itu, dengan melalui khalwat, perhatian peserta didik bisa dikosongkan dari kesibukan sosial media yang memalingkan dari pembelajaran melalui khalwat parsial. Di mana berhenti sesaat untuk konsentrasi sepenuh hati untuk mengingat Allah dan segera bertobat dari berbagai macam kesalahan baik besar maupun kecil sambil terus-menerus menyibukkan diri dengan zikir-zikir pilihannya. Atau metode khalwat pararel yaitu menyibukkan hati untuk mengingat Allah, meskipun anggota tubuhnya sedang beraktivitas dengan KBM maupun yang lainnya. Sehingga moto belajarnya "hati bersama sang khalik, sedangkan tubuh bersama KBM" dalam arti, ia bersama Allah dengan rohaninya dan bersama makhluk dengan jasmaninya.

Ritual khalwat juga bisa dijadikan sebagai ajang penyegaran psikologi para peserta didik dari stres, kepenatan dan kebosanan, karena ketika khalwat berlangsung, terdapat tiga tahap proses kejiwaan yang disebut separation, initiation dan return. Separation adalah proses memisahkan diri dari keramaian, kemudian initiation adalah proses menciptakan kesendirian dan kesunyian, dengan berkonsentrasi dan menukik jauh ke dalam diri, lalu menemukan pencerahan, akhirnya return adalah kembali ke kancah pergaulan masyarakat dengan suasana segar dan visi baru.

Oleh karena itu, implementasi khalwat pada proses pembelajaran daring adalah pada tahapan separation peserta didik bisa disuruh oleh gurunya untuk menyepi dan menyendiri sejenak lalu pada tahapan Initiation disuruh untuk berkonsentrasi dan 
menukik ke dalam dirinya kemudian pada tahapan return maka diharapkan peserta didik kembali ke dalam proses KBM dengan suasana segar, mental prima dan visi baru yang lebih unggul. Seorang sufi pada tahapan awal khalwat, biasanya akan dijenguk oleh gurunya dipetang hari untuk melihat kemajuannya atau membawanya kembali ke dunia normal jika terbukti ia terlalu lemah untuk melakukan latihan-latihan yang diwajibkan itu. Oleh karena itu, murid yang sedang melakukan metode khalwat juga harus senantiasa dipantau oleh gurunya dengan melalui program kunjungan ke rumah (home visit) atau meminta bantuan kepada orang tuanya untuk memantau perkembangannya.

\section{Kesimpulan}

Metode pembelajaran dengan sistem daring menimbulkan berbagai permasalahan baik kepada para peserta didik dan para orang tua berupa bosan, jenuh dan stres hingga tindakan bunuh diri. Oleh karena itu, metode khalwat sangat relevan sebagai alternatif pembelajaran pada masa pandemi sebagai bentuk penghayatan dan pengamalan agama yang sesuai dengan syariat. Bahkan dapat menjadi modal dasar untuk penanggulangan gangguan jiwa dari dimensi spiritual bagi para peserta didik yang stres, bosan dan jenuh akibat kurang bermain dan dibatasi kegiatan di keluar rumah. Oleh karena itu, study from home atau work from home hendaknya digunakan sebagai kesempatan untuk menerapkan metode khalwat. Kegiatan khalwat yang dilakukan tidak hanya untuk mengembangkan potensi diri tetapi juga untuk mendekatkan diri kepada Allah, sehingga memperoleh kasyf dan dzawq. Bahkan setelah proses khalwat akan lahir pribadi-pribadi yang kuat (return), bukan pribadi yang asing terhadap lingkungannya.

\section{Daftar Pustaka}

Abdillah, R. F. (2021). Pendidikan Tasawuf masyarakat Urban di Pondok Pesantren Baiturrohmah Kota Malang [Masters, Universitas Islam Negeri Maulana Malik Ibrahim]. http://etheses.uin-malang.ac.id/25813/

Aini, P. F., \& Rosyad, R. (2019). Khalwat dalam Mengendalikan Emosi. Syifa al-Qulub, 3(2), 53-64. https://doi.org/10.15575/saq.v3i2.4321

Al-Hamat, A., Mujahidin, E., Tamam, A. M., \& Hafidhuddin, D. (2016). Pendidikan Jihad Menurut Imam Bukhari (Studi Naskah Hadits-Hadits Kitab al Jihad Dalam Shahih Bukhari). Ta'dibuna: Jurnal Pendidikan Islam, 5(2), 204-237. https://doi.org/10.32832/tadibuna.v5i2.588

Al-Qusyairy, A. Q. (2008). Ar-Risalah al-Qusyairiah. Darul Mahabbah al-Baidha'.

Ananda, S. S. D., \& Apsari, N. C. (2020). MENGATASI STRESS PADA REMAJA SAAT PANDEMI COVID-19 DENGAN TEKNIK SELF TALK. Prosiding Penelitian dan Pengabdian kepada Masyarakat, 7(2), 248-256. https://doi.org/10.24198/ippm.v7i2.29050

Anwar, S. (2007). Filsafat Ilmu Ghazali, Dimensi Ontologi dan Aksiologi. Pustaka Setia.

Ardiansyah, M., Hafidhuddin, D., Mujahidin, E., \& Syafrin, N. (2017). The Concept of Adâb by Syed Muhammad Naquib al-Attas and Its Relevance to Education in Indonesia. 
International Journal of Islamic Education Ta'dibuna, 1(1), 53-64.

Az-Zamakhsyari, M. (2008). Tafsir al-Kasysyaf. Darul Maktabah.

Bin Baz, A. A. (1423). Majmu' Fatawa wa Maqalaatun Mutanawi'ah. Muassasah alHaramain al-Khairiyah.

Daradjat, Z. (2016). Kesehatan Mental. P.T Gunung Agung.

Drewes, G. J. W. (2002). Perdebatan Walisongo Seputar Ma'rifat. Al-Fikr.

Fahmi, M. (1977). Kesehatan Mental Dalam Keluarga, Sekolah dan Masyarakat. Bulan Bintang.

Farid, A. (2018). Tazkiah al-Nufuus. Pustaka Imam as-Syafi'I.

Fuad, I. (2016). Menjaga Kesehatan Mental Perspektif Al-Qur'an dan Hadits. Journal AnNafs: Kajian Penelitian Psikologi, 1(1), 31-50. https://doi.org/10.33367/psi.v1i1.245

Gani, A. (2019). PENDIDIKAN TASAWUF DALAM PEMBENTUKAN KECERDASAN SPIRITUAL DAN AKHLAKUL KARIMAH. Al-Tadzkiyyah: Jurnal Pendidikan Islam, 10(2), 275-286. https://doi.org/10.24042/atjpi.v10i2.5847

Goleman, D. (2020). Emotional Intelligence, Kecerdasan Emosional. P.T Gramedia Pustaka Utama.

Hamka. (2015). Tasawuf Modern. Penerbit Republika.

Hawari, D. (1997). Al-Qur'an Ilmu Kedokteran Jiwa dan Kesehatan Jiwa. P.T Dana Bhakti Prima Jasa.

Ibnu Khaldun, A. (2004). Muqadimah Ibnu Khaldun. Darul Fajr.

Ibnul-Jauzi, A. (2017). Shaidul Khathir. Madar al-Wathan.

Ibnul-Jauzi, A. F. (2004). At-Tabshirah. al-Maktabah al-Ashriyah.

Ibnul-Qayyim, M. (2001). Al-Fawaid. Dar al-Wathan.

Ibnul-Qayyim, M. (2005). Madarij As Salikin. Dar al-Hadits.

Ibrahim, I., Mujahidin, E., \& Saefudin, D. (2014). Analisis Terhadap Komunikasi Pembelajaran di Lembaga Pendidikan Islam: Studi Kasus di MAN Kabupaten Karawang. Ta'dibuna: Jurnal Pendidikan Islam, 3(2), 122-140. https://doi.org/10.32832/tadibuna.v3i2.567

Ibrahim, M. Z. (1995). Usul al Wusul: Adilat 'ahami ma'alim al sufiyat alhaqqati min sarih alkitaab wasahih alsunnah. Al Asyiratul Muhammadiyah.

Ibrahim, M., Z, A. H., Abdul Qadir, H., \& Ali Najjar, M. (t.t.). Al-Mu'jam al-Wasith. al-Maktbah al-Islamiyah.

Ikhsan, D., Fahmi, M. I., \& Mafan, A. (2017). Model Psikoterapi Zikir dalam Meningkatkan Kesehatan Mental. Academica : Journal of Multidisciplinary Studies, 1(2), 273-283.

Imron, I., \& Imron, I. (2015). Dorongan Fisiologis, Psikis Dan Spiritual Dalam Al Qur'An. Jurnal Tarbiyatuna, 6(1), 22-29.

Lubis, A. (2016). Peran agama dalam kesehatan mental. Ihya al-Arabiyah: Jurnal Pendidikan Bahasa dan Sastra Arab, 2(2).

Mustofa, A. (2018). Pendidikan Tasawuf Solusi Pembentukan Kecerdasan Spiritual dan Karakter. INOVATIF: Jurnal Penelitian Pendidikan, Agama Dan Kebudayaan, 4(1), 111-139.

Notosoedirjo, M. \& Latipun. (2014). Kesehatan Mental. Penerbit Universitas Muhammadiyah Malang.

Promm, E. (1995). Masyarakat Yang Sehat. Yayasan Obor Indonesia. 
Putri, A. W., Wibhawa, B., \& Gutama, A. S. (2015). KESEHATAN MENTAL MASYARAKAT INDONESIA (PENGETAHUAN, DAN KETERBUKAAN MASYARAKAT TERHADAP GANGGUAN KESEHATAN MENTAL). Prosiding Penelitian dan Pengabdian kepada Masyarakat, 2(2), Article 2. https://doi.org/10.24198/ippm.v2i2.13535

Ridlo, I. A. (2020). Pandemi COVID-19 dan Tantangan Kebijakan Kesehatan Mental di Indonesia. INSAN Jurnal Psikologi dan Kesehatan Mental, 5(2), 162-171. https://doi.org/10.20473/jpkm.V5I22020.162-171

Sismanto, H. B. (2013). Pendidikan Spiritual Model Khalwat di Pondok Pesantren Baitur Rohmah Malang Jawa Timur. IAIN Walisongo.

Suhaimi, S. (2016). GANGGUAN JIWA DALAM PERSPEKTIF KESEHATAN MENTAL ISLAM. An-Nida', 40(1), 23-30. https://doi.org/10.24014/an-nida.v40i1.1492

Sumantri, J. S. (2005). Filsafat ilmu: Sebuah pengantar populer. Jakarta: Sinar Harapan.

Syamsuddin, Z. A. (2015). Ritual Ramadhan Antara Adat dan Syariat. Pustaka Imam Bonjol. 